Faith-based Schools and the State. Catholics in America, France and England | In Good Faith. Schools, Religion and Public Funding

Harry Judge, Symposium Books, 2001, 279 p. | Marie Parker-Jenkins, Dimitra Hartas, Barrie A. Irving, Ashgate, 2005, 243 p.

Maroussia Raveaud

\title{
OpenEdition
}

Édition électronique

URL : http://journals.openedition.org/ries/1183

DOI : 10.4000/ries. 1183

ISSN : 2261-4265

Éditeur

Centre international d'études pédagogiques

Édition imprimée

Date de publication : 1 septembre 2005

Pagination : 13-15

ISBN : 978-2-85420-564-0

ISSN : $1254-4590$

Référence électronique

Maroussia Raveaud, «Faith-based Schools and the State. Catholics in America, France and England I In Good Faith. Schools, Religion and Public Funding », Revue internationale d'éducation de Sèvres [En ligne] 39 | septembre 2005, mis en ligne le 17 novembre 2011, consulté le 22 septembre 2020. URL : http:// journals.openedition.org/ries/1183 ; DOI : https://doi.org/10.4000/ries.1183

Ce document a été généré automatiquement le 22 septembre 2020

(C) Tous droits réservés 


\section{Faith-based Schools and the State. Catholics in America, France and England | In Good Faith. Schools, Religion and Public Funding}

Harry Judge, Symposium Books, 2001, 279 p. | Marie Parker-Jenkins, Dimitra Hartas, Barrie A. Irving, Ashgate, 2005, 243 p.

\section{Maroussia Raveaud}

\section{RÉFÉRENCE}

Faith-based Schools and the State. Catholics in America, France and England. Harry Judge, Symposium Books, 2001, $279 \mathrm{p}$.

In Good Faith. Schools, Religion and Public Funding. Marie Parker-Jenkins, Dimitra Hartas, Barrie A. Irving, Ashgate, 2005, 243 p.

1 Les deux ouvrages partagent des problématiques fondamentales : place de la religion à l'école; exploration des relations complexes entre identité religieuse et identité nationale, questionnement quant à l'incidence éventuelle des écoles confessionnelles sur la cohésion sociale. Ceci étant, leurs objets et leurs approches sont par ailleurs fortement distincts. Judge adopte une démarche comparative et historique pour étudier l'enseignement catholique aux États-Unis, en France et en Angleterre. ParkerJenkins et alii se penchent sur des établissements bien particuliers en Angleterre. Il s'agit d'écoles confessionnelles d'un genre nouveau, qui ont obtenu récemment un financement public, et se distinguent par le fait qu'elles correspondent à des religions pratiquées par les populations issues de l'immigration. Depuis l'arrivée au pouvoir des travaillistes en 1997 ont ainsi été créées ou intégrées dans le secteur public cinq écoles musulmanes, une sikh et une grecque orthodoxe. 
2 Le point de rencontre des deux ouvrages concerne l'école confessionnelle en Angleterre. C'est un pays où l'intervention publique en matière éducative a été pensée en complément aux initiatives religieuses et non dans une logique de substitution ou d'opposition. Aujourd'hui, tous les établissements publics font une part à la religion. Toute école est tenue d'assurer un enseignement religieux et un rassemblement matinal à caractère religieux (assembly). Dans les écoles communales, la loi stipule que les enseignements ne doivent pas relever d'un catéchisme particulier, tout en reflétant le fait que le pays est majoritairement chrétien. Par ailleurs, un tiers des écoles du secteur public sont des écoles confessionnelles. Selon le degré d'indépendance qu'elles souhaitent, notamment en matière d'éducation religieuse, l'État les finance à $90 \%$ ou $100 \%$ de leurs coûts. En dehors du secteur public existent enfin des écoles totalement privées, dont les public schools aristocratiques au nom trompeur, et aussi des écoles confessionnelles. Ces dernières peuvent être privées par choix, pour maintenir leur liberté vis-à-vis des contraintes qui accompagnent le financement public, ou parce que leur demande d'incorporation au secteur public a été refusée.

3 L'ouvrage de Judge adopte une démarche originale, évitant un plan strictement chronologique, thématique ou géographique. Il débute par six biographies de personnages emblématiques La France est représentée par François Guizot, seul protestant des six, et par Émile Combes, architecte militant de la séparation entre l'Église et l'État. La suite de l'ouvrage plonge le lecteur dans les trois arènes où s'est joué le sort de l'enseignement catholique : les cours de justice (pour les États-Unis), la rue (France) et le parlement (Angleterre). L'historien appréciera l'art de la narration historique et la densité du matériau employé, le prix à payer étant que les débats plus récents sont moins présents. L'intérêt majeur de ce livre est de mettre en évidence l'importance déterminante des contextes culturels, historiques et sociaux: la notion même d'école catholique est profondément marquée par le fait d'accueillir des immigrés sans le sou ou d'être sélective financièrement et scolairement; par le fait d'être demandée pour des raisons religieuses ou dans une logique de choix du consommateur; par l'idée qu'il est possible ou non d'être un bon catholique et en même temps un bon patriote, un sujet loyal, ou encore un bon républicain.

4 Les écoles catholiques scolarisent environ $5 \%$ des élèves américains, $10 \%$ en Angleterre et $17 \%$ en France. À côté de cela, le terrain du second ouvrage est statistiquement insignifiant : la portée des écoles confessionnelles créées en Angleterre depuis 1997 est avant tout symbolique et politique. Ainsi, les écoles musulmanes ne sont pas un phénomène nouveau : depuis 1979, elles sont une centaine à fonctionner comme écoles privées, accueillant $1 \%$ de la population musulmane en âge scolaire. Le fait marquant du gouvernement travailliste est d'avoir reconnu ces écoles à égalité avec les établissements protestants, catholiques et juifs, et de leur avoir ouvert l'accès aux fonds publics aux mêmes conditions qu'aux religions financées depuis le XIXe siècle. In Good Faith est une mine d'informations couvrant les aspects législatifs, financiers et pédagogiques touchant aux écoles confessionnelles, et offrant un aperçu précieux de ces établissements encore si mal connus. Les passages théoriques et conceptuels ne sont pas les plus convaincants; c'est la richesse des données concrètes et la présentation de la pluralité des points de vue qui fait la force du livre. C'est ainsi que la parole est donnée aux défenseurs de l'enseignement confessionnel pour attaquer le postulat de neutralité professé par les écoles communales : selon eux, la laïcité, même dans l'enseignement des sciences, loin d'être neutre ou compatible avec toutes les 
orientations spirituelles, repose sur une certaine philosophie de la vie qu'elle contribue activement à promouvoir. Ils y voient un "endoctrinement", retournant la critique habituellement faite à l'encontre des écoles religieuses. Le livre ébranle plus d'une idée reçue et insiste sur la diversité entre écoles confessionnelles : loin de l'image "select ", beaucoup d'écoles catholiques accueillent des populations socialement défavorisées; l'école grecque orthodoxe accueille presque une moitié d'élèves non grecs, dont une large proportion d'Antillais, et elle est perçue comme une école de la seconde chance pour des enfants en échec ailleurs; la plupart des écoles musulmanes ne sont pas réservées aux seuls musulmans. Les auteurs parviennent à soulever des questions épineuses en restant les plus objectifs possibles, et en évitant généralement les excès du politiquement correct.

5 Les débats britanniques sur l'enseignement confessionnel dépassent toutefois la question strictement religieuse. S'y superpose d'abord un enjeu de résultats scolaires et les auteurs remettent en question l'idée selon laquelle les écoles confessionnelles obtiennent de meilleurs résultats. En second lieu, ces débats s'inscrivent dans un horizon politique plus large: Tony Blair est un fervent défenseur de l'enseignement confessionnel et poursuit la construction d'un marché scolaire caractérisé par l'abolition de la carte scolaire et le développement d'une offre variée où la religion devient un élément parmi d'autres offert au choix parental aux côtés du caractère mixte ou non de l'école, son domaine de spécialisation ou encore son degré de sélectivité.

6 In Good Faith s'achève sur un tour d'horizon des enjeux que soulèvent ces nouvelles écoles confessionnelles : quelle est la place des «minorités ethniques» dans le pays? L'égalité est-elle toujours une revendication pertinente face aux attentes de reconnaissance des identités culturelles, ethniques et religieuses ? Comment la société dans son ensemble doit-elle évoluer et repenser ce que signifie être britannique aujourd'hui ? À partir d'une étude des écoles confessionnelles, ces deux ouvrages contribuent à alimenter des réflexions fondamentales sur le sens de l'égalité et la justice sociale dans des contextes scolaires caractérisés par la diversité et, en France, par le débat sur la laïcité.

\section{INDEX}

Index géographique : Angleterre, Royaume-Uni, États-Unis, France

\section{AUTEURS}

MAROUSSIA RAVEAUD

Maître de conférences à l'Université du Maine 